\title{
WHY SHOULD WE STILL CARE ABOUT THE STAVUDINE DOSE?
}

\author{
Steve Innes ${ }^{1}, M B B C h, M R C P C H, M P h i l$ \\ Mark Cotton ${ }^{1}, M B C h B, M M e d, F C P a e d, D T M \& H, D C H(S A), P h D$ \\ François Venter ${ }^{2}, M B B C h, F C P(S A)$, Dip HIV Man (SA), DTM\&H (SA), MMed \\ ${ }^{1}$ Children's Infectious Diseases Clinical Research Unit (KID-CRU), Tygerberg Children's Hospital and Stellenbosch University, W Cape \\ ${ }^{2}$ Wits Reproductive Health and HIV Institute (WRHI), Department of Medicine, University of the Witwatersrand and \\ Johannesburg Academic Hospital
}

\begin{abstract}
Current recommendations advise that stavudine be phased out of use. The logistics and cost of switching are significant, and the World Health Organization has forecast that 1.55 million people will still be on stavudinebased antiretroviral therapy by the end of 2012. Stavudine is co-formulated in many countries, is very cheap and effective, and is well tolerated in initial therapy. However, the $40 \mathrm{mg} \mathrm{BD}$ dose was associated with considerable long-term toxicity. Several studies suggest that half the original recommended dose has excellent antiviral efficacy with significantly reduced metabolic side-effects. Despite generic tenofovir now being cheaper than zidovudine, tenofovir consumes the majority of adult antiretroviral programme medication budgets in programmes in Africa, where it is used in first-line therapy. Abacavir is far more expensive than zidovudine or tenofovir, and is a major cost driver in paediatric programmes with access to abacavir-based first-line treatment. Low-dose stavudine may offer the only cheaper (and possibly as effective and safe) alternative to programmes grappling with limited financial resources.
\end{abstract}

The UNAIDS 2010 global report estimated that 20 million adults and 2.3 million children in sub-Saharan Africa are HIV-infected, ${ }^{1}$ of whom 6.7 million and 518000 , respectively, are currently on antiretroviral therapy (ART). ${ }^{2-3}$ In the late 1990s stavudine was selected as the first-line antiretroviral of choice for adults and children in the developed world because it is extremely safe in the short term, in contrast to the toxicity and intolerance associated with zidovudine. In fact, stavudine was regarded as so safe that the original recommended dose for adults was $40 \mathrm{mg}$ twice daily (BD), even though a number of randomised clinical trials had shown that it was equally effective at a dose of $20 \mathrm{mg} \mathrm{BD} .^{4-7}$ Forty milligrams BD was chosen fairly arbitrarily over $20 \mathrm{mg}$ BD after the Stavudine 019 trial $^{8}$ chose to test $40 \mathrm{mg}$ twice daily rather than a lower dose, and found that stavudine had minimal short-term toxicity at that dose. The children's dose was extrapolated from the adult dose using data from paediatric pharmacokinetic studies that showed that an oral dose of $1 \mathrm{mg} / \mathrm{kg} /$ dose twice daily in children weighing under $30 \mathrm{~kg}$ results in plasma exposure similar to that of an adult over $60 \mathrm{~kg}$ taking $40 \mathrm{mg}$ twice daily, and that an oral dose of $0.5 \mathrm{mg} / \mathrm{kg} /$ dose twice daily in children results in plasma exposure similar to that of an adult over $60 \mathrm{~kg}$ taking $20 \mathrm{mg}$ twice daily. ${ }^{9-10}$ No virological outcomes were reported in those paediatric pharmacokinetic studies.

ART-associated lipoatrophy was first described in $1998,{ }^{11} 4$ years after the introduction of stavudine as an antiretroviral agent. By 2002, lipoatrophy was recognised as a frequent delayed adverse effect of stavudine. ${ }^{12} \mathrm{~A}$ large number of studies have since shown a causal link with nucleoside reverse transcriptase inhibitor exposure, particularly didanosine, stavudine and zidovudine, of which stavudine shows the strongest link. The effect of stavudine in causing lipoatrophy appears to be strongly dose-related, and in 2007 the World Health Organization advised that the recommended adult dose be lowered from 40 to $30 \mathrm{mg} \mathrm{BD.}$. $^{13-14}$ The children's dose was not lowered, however, because lipoatrophy was believed to be uncommon in children (although this assumption is currently being refuted). The lipoatrophy caused by stavudine typically does not manifest until $18-24$ months of therapy, and even then may go unnoticed or may not be taken seriously by the health care provider for months or years as it slowly progresses. The typically long delay between drug initiation and manifestation of toxicity may have contributed to the delay in the global response in reducing the recommended dose from 40 to $30 \mathrm{mg} \mathrm{BD}$. In the meantime, stavudine has gained a bad reputation due to the stigmatising effect of lipoatrophy, which resolves slowly and poorly. However, evidence accumulated over the last 15 years suggests that stavudine given at the equivalent of $20 \mathrm{mg} \mathrm{BD}$ leads to a significantly lower rate of lipoatrophy and of other mitochondrial adverse effects. ${ }^{13,15-17}$

The logistics and cost of switching all antiretroviraltreated individuals to non-stavudine therapy is significant. Generic tenofovir costs 6 times more per month than stavudine, while tenofovir co-formulated with emtricitibine costs 4 times more than a month's supply of stavudine and lamivudine combined. ${ }^{18}$ In 
addition, the use of tenofovir, which requires additional renal function monitoring, substantially increases the programme costs of safety monitoring. ${ }^{19}$ Taking the costs of toxicity management into account, the costeffectiveness ratio (measured in cost per year of life saved) of tenofovir is double that of stavudine (when ART is initiated at $350 \mathrm{CD} 4$ cells $/ \mu$ in a one-line setting) with similar 5 -year survival $(89 \%$ v. $87 \%)$ when using the incidence of stavudine toxicity associated with $40 \mathrm{mg}$ $\mathrm{BD} .{ }^{20}$ Since the incidence of late adverse events due to stavudine is likely to be substantially reduced by using a more appropriate dose $(20 \mathrm{mg} \mathrm{BD})$, the advantages of tenofovir over stavudine may begin to dwindle. Given the escalating number of people being initiated on ART and the stress this places on existing ART programmes, it is unlikely that switching stable patients from stavudine to an alternative will be a high priority. In addition, for those initiated on alternative ART regimens, stavudine will probably remain an important secondline agent, especially in patients unable to tolerate or have affordable access to zidovudine or abacavir. Using stavudine in first-line therapy further preserves tenofovir for second line. Both the World Health Organization and the Clinton Health Access Initiative have forecast that approximately 1.4 million adults ( $18 \%$ of adults on ART) and 150000 children ( $26 \%$ of children on ART) will still be on stavudine-based ART by the end of $2012^{3}$ (personal communication, Joanna Sickler, Clinton Health Access Initiative). The authors therefore advocate a head-tohead randomised controlled trial comparing stavudine $20 \mathrm{mg} \mathrm{BD}$ with tenofovir $300 \mathrm{mg}$ once daily, powered to show non-inferiority in adults.

\section{REFERENCES}

1. UNAIDS. Report on the Global AIDS Epidemic. 2010. http://www.unaids.org/ globalreport/global_report.htm (accessed 8 September 2011).

2. Renaud-Thery F, Avila-Figueroa C, Stover J, et al. Utilization patterns and projected demand of antiretroviral drugs in low- and middle-income countries. AIDS Research and Treatment 2011;2011. doi:10.1155/2011/749041. http://www.hindawi.com/ journals/art/2011/749041/ctal (accessed 15 November 2011).
3. World Health Organization. Forecasting antiretroviral demand. 2010. http://www. who.int/hiv/amds/forecasting/en/index4.html (accessed 15 September 2011).

4. Anderson RE, Dunkle LM, Smaldone L, et al. Design and implementation of the stavudine parallel-track program. J Infect Dis 1995;171(suppl 2):S118-122.

5. Petersen EA, Ramirez-Ronda CH, Hardy WD, et al. Dose-related activity of stavudine in patients infected with human immunodeficiency virus. J Infect Dis 1995;171(suppl 2):S131-139.

6. Pollard RB, Peterson D, Hardy D, et al. Safety and antiretroviral effects of combined didanosine and stavudine therapy in HIV-infected individuals with CD4 counts of 200 to 500 cells/mm3. J Acquir Immune Defic Syndr 1999;22(1):39-48.

7. Ruxrungtham K, Kroon ED, Ungsedhapand $C$, et al. A randomized, dose-finding study with didanosine plus stavudine versus didanosine alone in antiviral-naive, HIV-infected Thai patients. AIDS 2000;14(10):1375-1382.

8. Spruance SL, Pavia AT, Mellors JW, et al. Clinical efficacy of monotherapy with stavudine compared with zidovudine in HIV-infected, zidovudine-experienced patients. A randomized, double-blind, controlled trial. Bristol-Myers Squibb Stavudine/019 Study Group. Ann Intern Med 1997;126(5):355-363.

9. Kaul S, Kline MW, Church JA, Dunkle LM. Determination of dosing guidelines for stavudine (2', 3'-didehydro-3'-deoxythymidine) in children with human immunodeficiency virus infection. Antimicrob Agents Chemother 2001;45(3):758763.

10. Kline MW, Dunkle LM, Church JA, et al. A phase I/II evaluation of stavudine (d4T) in children with human immunodeficiency virus infection. Pediatrics 1995;96:247-252.

11. Carr A, Samaras K, Burton S, et al. A syndrome of peripheral lipodystrophy, hyperlipidaemia and insulin resistance in patients receiving HIV protease inhibitors. AIDS 1998:12(7):F51-58.

12. Joly V, Flandre P, Meiffredy V, et al. Increased risk of lipoatrophy under stavudine in HIV-1-infected patients: results of a substudy from a comparative trial. AIDS 2002;16(18):2447-2454

13. Hill A, Ruxrungtham K, Hanvanich M, et al. Systematic review of clinical trials evaluating low doses of stavudine as part of antiretroviral treatment. Expert Opin Pharmacother 2007:8(5):679-688.

14. World Health Organization. Addendum to 2006 WHO Guidelines on Antiretroviral Therapy for HIV Infection in Adults and Adolescents. 2007. http://www.who.int/hiv/ art/ARTadultsaddendum.pdf (accessed 26 August 2008).

15. McComsey GA, Lo Re V 3rd, O'Riordan M, et al. Effect of reducing the dose of stavudine on body composition, bone density, and markers of mitochondrial toxicity in HIV-infected subjects: a randomized, controlled study. Clin Infect Dis 2008;46(8):1290-1296.

16. Milinkovic A, Martinez E, Lopez S, et al. The impact of reducing stavudine dose versus switching to tenofovir on plasma lipids, body composition and mitochondrial function in HIV-infected patients. Antivir Ther 2007;12(3):407-415

17. Sanchez-Conde M, de Mendoza C, Jimenez-Nacher I, Barreiro P, Gonzalez-Lahoz J, Soriano V. Reductions in stavudine dose might ameliorate mitochondrial-associated complications without compromising antiviral activity. HIV Clin Trials 2005;6(4):197202 .

18. Southern African HIV Clinicians Society. Antiretroviral pricelist. 2010. http://www. sahivsoc.org/indexARV.php/arvpricelist (accessed 1 September 2011).

9. Wood R. The role of stavudine in the South African public sector antiretroviral programme: Should the perfect be the enemy of the good? Southern African Journal of HIV Medicine 2006;7(2):5-8

20. Walensky RP, Wood R, Ciaranello AL, et al. Scaling up the 2010 World Health Organization HIV Treatment Guidelines in resource-limited settings: a model-based analysis. PLoS Med 2010;7(12):e1000382. 